\title{
Detecção e predição de estados afetivos baseadas em mineração de dados educacionais: considerando a personalidade do aluno para aumentar a precisão da detecção
}

\author{
Felipe de Morais ${ }^{1}$, Patricia A. Jaques ${ }^{1}$ \\ ${ }^{1}$ Programa de Pós-Graduação em Computação Aplicada (PPGCA) \\ Universidade do Vale do Rio dos Sinos (UNISINOS), São Leopoldo - RS - Brasil \\ felipmorais@edu.unisinos.br, pjaques@unisinos.br
}

As emoções, um tipo de estado efetivo, interferem no processo de aprendizagem, bem como no engajamento dos alunos. Assim, é importante que ambientes educacionais, como os Sistemas Tutores Inteligentes (STIs), também possuam a habilidade de reconhecer as emoções dos estudantes e responder adequadamente. Esse trabalho tem como objetivo detectar os estados de frustração, confusão, tédio e engajamento dos alunos por meio da mineração dos dados em STIs baseados em passos. A hipótese de pesquisa deste trabalho é que a inserção de características da personalidade dos alunos no treinamento dos detectores pode resultar em uma melhora na precisão da detecção destes quatro estados, pois sabe-se que a personalidade influencia os estados afetivos e sua duração. $\mathrm{O}$ método utilizado foi o desenvolvimento de detectores treinados com e sem dados de personalidade. Para a obtenção dos dados de treinamento destes detectores, foi realizada uma coleta de dados com 55 alunos que utilizaram o STI PAT2Math durante 10 sessões, tendo seus rostos gravados, juntamente com áudio e a tela do seu computador. Foi selecionado um total de $5525 \operatorname{logs}$ de interação entre o aluno e o sistema, sendo que para cada um desses $\log s, 348$ características foram calculadas, contendo informações provenientes $(i)$ das interações do aluno com a interface do PAT2Math, (ii) do módulo do aluno, (iii) dos traços de personalidade e (iv) dos estados afetivos e comportamentos dos alunos. Ao analisar os vídeos obtidos, foram gerados 2099 rótulos de estados afetivos e 2059 de comportamentos dos alunos por meio do protocolo EmAP-ML. Foram desenvolvidos dois detectores para cada estado afetivo, sendo uma versão treinada com os dados de personalidade e outra treinada sem, permitindo verificar o impacto da personalidade na detecção dos estados afetivos. Como resultado, foi possível identificar que apenas o detector de engajamento, treinado com dados da personalidade dos alunos, obteve uma pequena melhora na precisão da detecção. Ainda, com o uso de um algoritmo de seleção de características, foi possível verificar que entre 348 características disponíveis, apenas dez foram selecionadas, incluindo dados da personalidade. Deste modo, este trabalho aponta indícios de que a personalidade pode impactar de forma positiva na detecção dos estados afetivos dos alunos em STIs. Esta contribuição vai em direção ao objetivo de realizar a detecção automática e em tempo real dos estados afetivos dos alunos, permitindo uma adaptação instantânea dos STIs de acordo com as emoções dos alunos [Morais and Jaques 2019] ${ }^{1}$.

\section{Referências}

Morais, F. and Jaques, P. A. (2019). Predição de emoções baseada em mineração de dados: considerando a personalidade para melhorar a detecção. In Simpósio Brasileiro de Informática na Educação (SBIE), volume 30.

\footnotetext{
${ }^{1}$ Versão completa do trabalho publicada nos anais do SBIE 2019.
} 